\title{
Aneurysmal Bone Cyst of Talus: A Rare Case
}

\author{
Kishor Taori, Ramesh Parate, Suresh Dhakate, Anand Hatgaonkar, Swenil Shah, \\ Akshat Kasat, Darshan Patwa, Chandrakant Kamble \\ Department of Radiodiagnosis, Government Medical College, Nagpur, India \\ Email: kasatakshat@gmail.com
}

Received 18 March 2015; accepted 8 June 2015; published 11 June 2015

Copyright (C) 2015 by authors and Scientific Research Publishing Inc.

This work is licensed under the Creative Commons Attribution International License (CC BY). http://creativecommons.org/licenses/by/4.0/

C. (i) Open Access

\begin{abstract}
Aneurysmal bone cyst is a benign locally aggressive lytic lesion usually involving metaphyseal regions of long tubular bones. It rarely involves talus. It can be primary or secondary in origin. We reported the imaging findings in a case of a 23-year-old male patient with complaints of pain and swelling around left ankle joint one year ago which turned out to be aneurysmal bone cyst on histopathology.
\end{abstract}

\section{Keywords}

\section{Aneurysmal Bone Cyst, Lytic Lesion, Talus, Bone Tumor}

\section{Introduction}

Aneurysmal Bone Cyst (ABC) represents about $1 \%$ of all primary bone tumors collectively [1]. The lesion was first described by Jaffe and Lichtenstein [2] in 1942, which subsequently became known as Jaffe-Lichtenstein disease. This tumor has a predilection for metaphyseal regions of long tubular bones and rarely involves talus, with less than 30 cases reported worldwide. It can be primary or secondary i.e. as a collision tumor along with other osseous lesions like Chondroblastoma, Giant Cell Tumor or Osteosarcoma, in about 30\% cases [3], affecting both diagnosis and prognosis as well.

\section{Case Report}

A 23-year-old male, presented to our hospital with complaints of pain around left ankle with limping since last 12 months. He did not have history of any significant trauma, swelling, fever, chills, sweats, weight loss or any other complains. Systemic examination was normal. Local clinical examination revealed mild swelling around the left ankle without any tenderness and no sign of inflammation or infection such as erythema, induration or local rise of temperature. Routine blood investigations including erythrocyte sedimentation rate and creative reactive protein were normal. Antero-posterior (AP) and lateral radiographs of the ankle (Figure 1) revealed 
well-defined lytic expansile lesion noted involving head, neck and body of talus with breech of cortex noted antero-superiorly and postero-inferiorly. However there was no collapse of talus. We considered giant cell tumor, aneurysmal bone cyst or simple bone cyst amongst the diagnostic differentials. No periosteal reaction or calcifications were noted. General body survey and a chest radiograph ruled out multi-centric diseases and metastasis . Since there was cortical breach, magnetic resonance imaging was ordered. Magnetic resonance Imaging (MRI) of the foot and ankle revealed solid-cystic lesion in the left talus, with solid component appearing iso to hyperintense to muscles on T1 (Figure 2) and T2 weighted sequences (Figure 3) and Fluid-fluid levels seen on

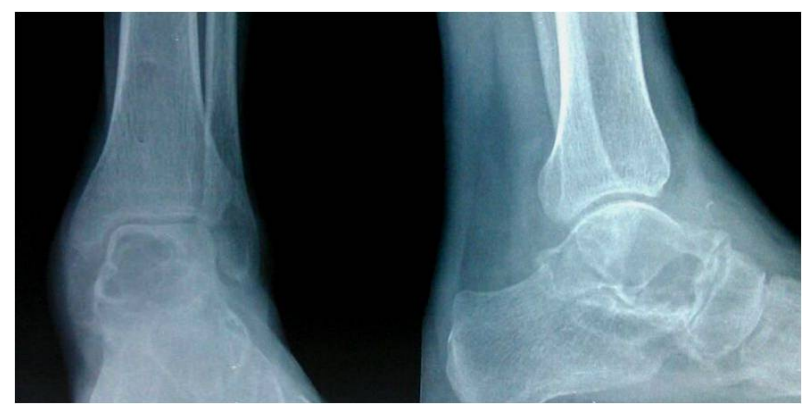

Figure 1. Lytic expansile lesion noted involving talus (broad arrow) with breach of cortex (thin arrow).

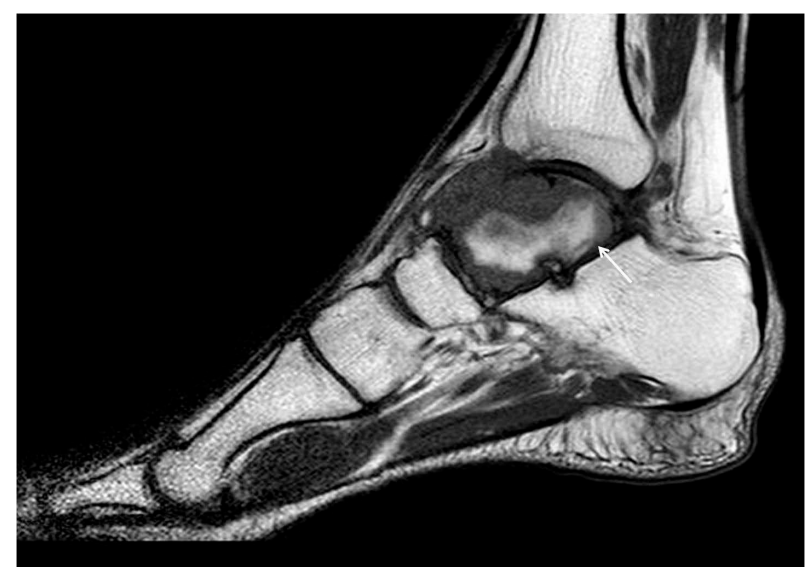

Figure 2. T1 weighted sagittal images showing iso to hyperintense lesion involving talus and extending to involve tibiotalar and talo-navicular joint. Arrow showing fluid-fluid level.

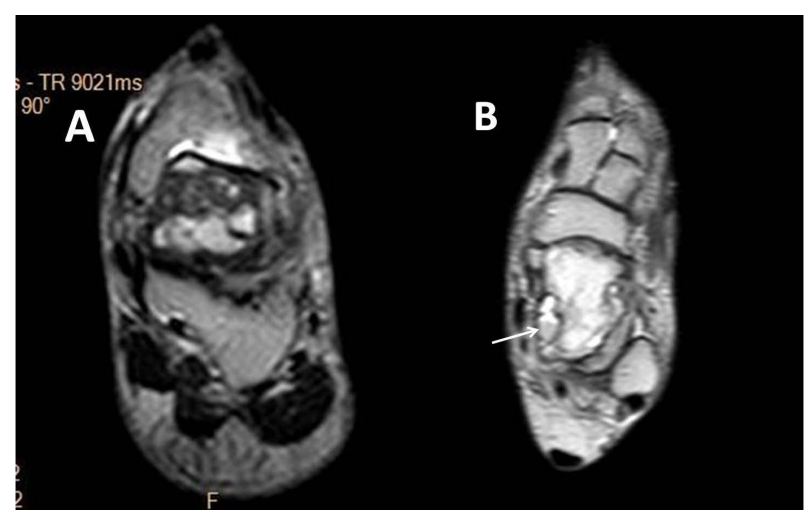

Figure 3. A T2 weighted coronal image; B PDW axial image with arrows showing fluid-fluid level. 
both the sequences (Figure 2 and Figure 3). The solid component showed enhancement with gadolinium (Figure 4). There was extension into the talo-navicular and tibio-talar joint space (Figure 2). Presence of associated soft tissue suggested secondary aneurysmal bone cyst more than primary [4]. On the basis of the clinical and imaging findings, a provisional diagnosis of aneurysmal bone cyst possibly secondary in origin was made. However biopsy from the lesion showed only findings of aneurysmal bone cyst with no evidence of any other underlying pathology. The nature of the lesion, the diagnostic differentials, different treatment options and possible outcomes were discussed at length with the patient and decision for extended intra-lesional curettage and autologous bone grafting was taken. Postoperative histo-pathological examination of the curettage material revealed findings consistent with aneurysmal bone cyst (Figure 5) with no features of any other underlying pathology in the specimen. Patient had no complains on 6 month follow up and radiograph showed no signs of recurrence of lesion.

\section{Discussion}

Aneurysmal bone cyst $(\mathrm{ABC})$ is a benign tumor like condition of the bone but it remains an enigma, not only regarding causation, but also regarding clinical and imaging diagnosis and optimal treatment. ABC represents about $1 \%$ of all primary bone tumors collectively [1] with a predilection for metaphyseal regions of long tubular bones. Talus is an unusual site for aneurysmal bone cyst; in fact the most common tumors of talus are intra-osseous ganglion cysts [5]. Most cases occur between the ages of $10-20$ years and show a slight female preponderance [6].

The aneurysmal bone cyst is probably the result of a trauma or a tumor-induced anomalous vascular process. Appropriate treatment of an aneurysmal bone cyst requires identification of a preexisting lesion, if possible. In approximately one third of cases only, the preexisting lesion can be clearly identified. The most common of these is the giant cell tumor, which accounts for $19 \%-39 \%$ of cases in which the preceding lesion is found [7].

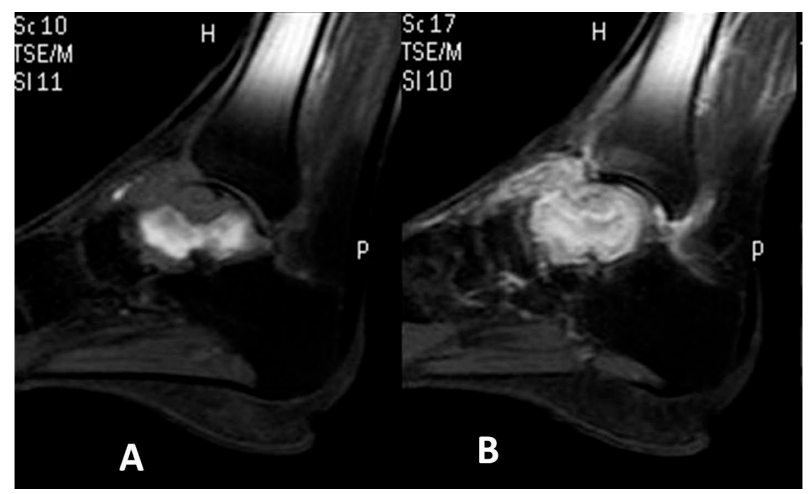

Figure 4. A precontrast and B post contrast sequences showing soft tissue enhancement.

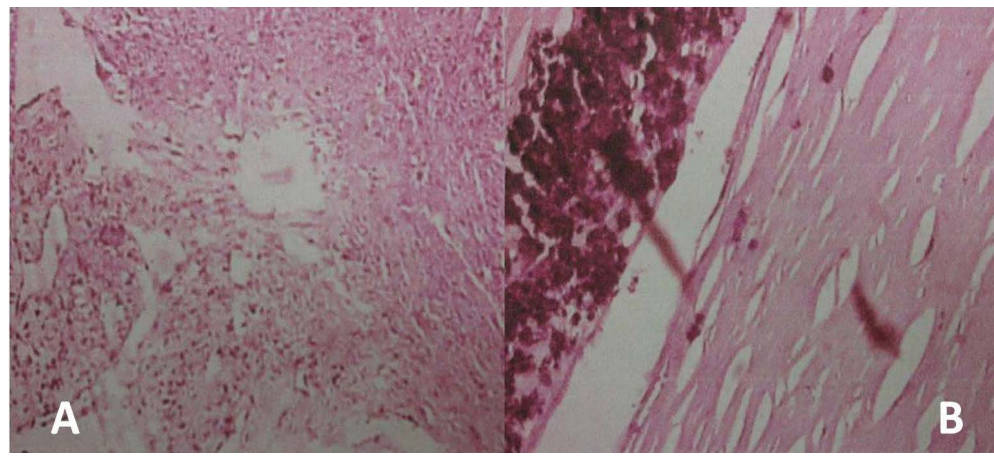

Figure 5. Histologic slides, hematoxylin-eosin [H-E] stain A blood filled cavities lined by fibrous septa; $\mathbf{B}$ occasional osteoclastic giant cells, haemosiderin laden macrophages. 
According to Chakarun et al., one means of differentiation between primary aneurysmal bone cyst and that secondary to giant cell tumor is the presence of an enhancing soft-tissue component, which may be seen in the latter but should not be present if the lesion is a primary aneurysmal bone cyst [4]. In our case despite the associated enhancing soft tissue, lesion turned out to be primary in nature. Many authors have described excellent results with intralesional curettage and bone grafting for lytic lesions that were well localized within the talus [8]-[10].

\section{Conclusion}

Though aneurysmal bone cyst of talus is rare, its possibility must not be forgotten when a patient presents with a lytic lesion in talus. It can be easily diagnosed on cross sectional imaging especially MRI. MRI also helps in visualizing the extent of the lesion, and its characterization, and in narrowing down differential diagnosis.

\section{References}

[1] Orthopaedics, D. (2007) Wheeless' Textbook of Orthopaedics, Aneurysmal Bone Cyst. Published Online.

[2] Jaffe, H.L. and Lichtenstein, L. (1942) Solitary Unicameralbone Bone Cyst with Emphasis on the Roentgen Picture, the Pathologic Appearance and the Pathogenesis. Archives of Surgery, 44, 1004-1025. http://dx.doi.org/10.1001/archsurg.1942.01210240043003

[3] Cottarolda, J. and Bourelle, S. (2007) Modern Concepts of Primary Aneurysmal Bone Cyst. Archives of Orthopaedic and Trauma Surgery, 127, 105-114. http://dx.doi.org/10.1007/s00402-006-0223-5

[4] Chakarun, C.J., Forrester, D.M., Gottsegen, C.J., Patel, D.B., White, E.A. and Matcuk Jr., G.R. (2013) Giant Cell Tumor of Bone: Review, Mimics, and New Developments in Treatment. Radiographics, 33, 197-211. http://dx.doi.org/10.1148/rg.331125089

[5] Pollandt, K., Werner, M. and Delling, G. (2003) Tumors of the Footbones: A Report from the Hamburg Bone Tumor Registry. Zeitschrift fur Orthopadie und ihre Grenzgebiete, 141, 445-451.

[6] Rosai, J. (2009) Bone and Joints. In: Rosai, J, Ed., Rosai and Ackerman's Surgical Pathology, 9th Edition, Mosby, Missouri, Primary Aneurysmal Cyst of Talus, 2188-2191.

[7] Kransdorf, M.J. and Sweet, D.E. (1995) Aneurysmal Bone Cyst: Concept, Controversy, Clinical Presentation, and Imaging. American Journal of Roentgenology, 164, 573-580. http://dx.doi.org/10.2214/ajr.164.3.7863874

[8] Luna, A.R., Fahandez-Saddi, H., Garcia, A.V., Reina Cde, J. and Martin, J.V. (2004) Aneurysmal Bone Cyst in Children Involving Infrequent Locations. Report on Two Cases. Chir Organi Mov, 89, 347-352.

[9] Dhillon, M.S., Singh, B., Gill, S.S., Walker, R. and Nagi, O.N. (1993) Management of Giant Cell Tumor of the Tarsal Bones: A Report of Nine Cases and a Review of the Literature. Foot \& Ankle, 14, 265-272. http://dx.doi.org/10.1177/107110079301400506

[10] Bapat, M.R., Narlawar, R.S., Pimple, M.K. and Bhosale, P.B. (2000) Giant Cell Tumour of Talar Body. Journal of Postgraduate Medicine, 46, 110-111. 